\title{
Training, performance and value of Latinas in the United States urology workforce.
}

\author{
Formación y desempeño de la mujer uróloga latina \\ en los Estados Unidos. \\ iD Natalia Hernández, ${ }^{1{ }^{*}}$ iD Ricardo René González. ${ }^{1}$
}

\begin{abstract}
With the increasing diversity in the population of the United States, efforts and interest in diversity in healthcare have followed. The article offers an insightful review of recent studies evalua-

Key words:

International Medical ting the role of women and underrepresented minorities (URM) in Urology in order to better understand the state of Latinas in Urology. We review the representation of women in urology residency in the United State (U.S.), international medical graduates (IMGs) in urology, and the most recent initiatives developed by urologists to increase diversity in the urological community to better reflect the communities served.

Graduates (IMG),

women in urology, underepresented minorities, diversity, equity, inclusion
\end{abstract}

Corresponding author: *Natalia Hernández. Female Pelvic Medicine Citation: Hernández N., González R.R. Training, performance and value of Latinas in the United States urology workforce. Rev Mex Urol. 2022;81(6):pp. 1-7

and Reconstructive

Surgery Fellow Houston Methodist

${ }^{1}$ Houston Methodist Hospital. Houston, Texas, United States.

Hospital 6560 Fannin, Suite 2100 Houston, Texas 770030. Email: nhernandez2@ houstonmethodist.org

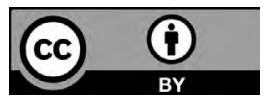




\section{Training, performance and value of Latinas in the United States urology workforce. Hernández N., et al}

\section{Palabras clave:}

Médicos Graduados Internacionales, mujeres en urología, minorías subrepresentadas, diversidad, equidad, inclusión

\section{Resumen}

Con la creciente diversidad en la población de los Estados Unidos, han seguido los esfuerzos y el interés en la diversidad en el cuidado de la salud. El artículo ofrece una revisión perspicaz de estudios recientes que evalúan el papel de las mujeres y las minorías subrepresentadas en Urología para comprender mejor el estado de las latinas en esta disciplina. Revisamos la representación de las mujeres en la residencia de urología en los Estados Unidos (EE. UU.), los graduados médicos internacionales en urología y las iniciativas más recientes desarrolladas por los urólogos para aumentar la diversidad en la comunidad urológica para reflejar mejor las comunidades a las que sirven.

\section{Introduction}

Diversity in the U.S. population has shown a steady increase in the last decades followed by an increased interest in diversity in healthcare to reflect the population that is served. ${ }^{(1)}$ Care from providers who share similar background, including gender for urology female patients but also racial and ethnic concordance in physician-patient relationship has been associated with higher patient satisfaction, decreased reports of patient mistreatment, and improved patient decision making. ${ }^{(1-3)}$ Despite awareness and interest, the increase in diversity in the U.S. population has rapidly outpaced the Urology workforce in the country. In the 2019 US Census, $18 \%$ of the population was Latinx/ Hispanic. $^{(3,4)}$ The most recent data from the American Urological Association (AUA) Census in 2020 showed that 497 (3.8\%) of practicing urologists, both male and female, were Latinx/Hispanic. ${ }^{(5)}$ Representation of women in the AUA Census increased since 2019, with a $10.3 \%$ of practicing women from $2 \%$ in 1980 , to $7.7 \%$ in 2013 and $10.3 \%$ on the most recent AUA census. ${ }^{(5,6)}$ However, the census does not provide a breakdown of Latina women currently practicing in the United States. ${ }^{(7)}$

Other than ethnic/language congruence between patients and physicians than serve them, there are other benefits of diversity in the healthcare workforce. Diverse teams may have better outcomes and are more innovative. (7) There is an impetus to improve representation of women and underrepresented minorities in medicine. Having said that, urology is lagging other fields in medicine in racial and ethnic diversity. ${ }^{(3,8)}$

\section{Women in urology residency in the U.S}

Even though women representation in Urology has shown a slow growth throughout the years, urology has traditionally been a male dominated field. Back in 1980, women represented less 
than $2 \%$ of the residents in training. ${ }^{(6)}$ Recently, Ghanney Simons et al. investigated the diversity in graduate medical education in Urology in the U.S. with a total of $5.7 \%$ Latinx/Hispanic urology residents. They highlight a key point in that diversity in the physician-scientist population will improve and ensure diversity in patient recruitment for research trials. This may be due to the innate trust that is easier to foster when the physician population mirrors the communities they serve. ${ }^{(7)}$

Marthi et al. evaluated the available data from the Accreditation Council for Graduate Medical Education (ACGME) from 2019 and 2020 and compared the information to the national racial, ethnic and gender distribution from the 2019 U.S. Census. This estimated that 60.7 million of the U.S. population were Hispanic/Latino, representing $18 \%$ of the total population. By calculating the percent differences in representation in urology residency programs in the U.S., the authors found that from 1734 urology residents, $27 \%$ were female and $14 \%$ were URM. When analyzing this data, results showed that women and URMs were significantly underrepresented in urology residency programs with a negative difference of $14 \% .^{(3)}$

Diversity in other medical specialties with greater Hispanic/Latinx representation include psychiatry, family medicine, obstetrics and gynecology, general surgery and internal medicine. ${ }^{(3,9)}$ Potential causes of underrepresentation from URM in urology can be explained by lack of URM mentors and structural barriers limiting URM from entering competitive specialties like urology. The shortage in URM urologists in academic leadership positions has been documented, with $96 \%$ being Non-Hispanic and $79.9 \%$ men. ${ }^{(10)}$ Additionally, there is a higher percentage of women physicians in the
URM applicant pool, and women, too, are underrepresented in urology. ${ }^{(3,11)}$

One other potential explanation for underrepresentation of URM and women in the urology match can be related to a different experience interacting with urology trainees and faculty before and during the application process. ${ }^{(12)}$ An anonymous survey of 136 applicants of the 2020 Urology Match showed that among $85 \%$ of applicants from URM reported that URM residents, faculty or leadership at an institution had a favorable impact on their rank list. Most importantly, URM ethnicity was an independent predictor for URM students ranking a program higher due to a higher proportion of residents, faculty or leadership. ${ }^{(12)}$

\section{International Medical Graduates in Urology}

Halpern et al examined Urology Match data from 1987 to 2015 to evaluate the trends of international medical graduates (IMG) representation within urology and compared it to other specialties. ${ }^{(13)}$ Match rates for U.S. medical graduates are between $68-90 \%$ compared to $6-33 \%$ for international medical graduates (IMG). Interestingly, the proportion of IMG in other specialties remained stable throughout the years, but in Urology there was a significant decline from $27 \%$ to $5 \%$ over three decades. The authors discuss different options to explain this decline, including the increase in U.S. medical graduates, also explained by the $17 \%$ expansion in U.S. Medical Schools. They also highlight the fact that Urology has become a highly competitive surgical specialty and the high cost of the match process. As part of the selection process, program directors place 
importance on the prestige of an applicant's medical school, and many of the prestigious international institutions may not be well known in the U.S. by those involved in the selection process. ${ }^{(13-15)}$

IMGs also face challenges beyond training, including isolation or insensitivity at work, as well as different degrees of discrimination. The authors highlight four areas where IMGs face challenge during residency: simultaneously navigate dual learning curves as immigrants and residents; insensitivity and isolation in the workplace; migration personal and global costs and specific IMG needs to complete residency training. ${ }^{(16)}$

IMGs play a key role contributing to diversity in the workforce particularly in academic research and help decrease the gap between the high demand for urologists in the country as the US population continues to grow. ${ }^{(13)}$

\section{Strategies}

Dai et al give an insightful perspective on strategies to improve recruitment and retention of URM and women in Urology. Focusing on increasing early exposure and opportunities for medical students, fostering networks, creating career mentorship during and after residency support the professional development of female urologists of URM. ${ }^{(1)}$

Early mentorship, a diverse faculty and residency cohorts that medical students can identify with has been associated with an increased number of students who match into urology. ${ }^{(1,17)}$ Continuing these strategies throughout residency that support URM and female urology residents during their surgical training will also impact retention of trainees. ${ }^{(1)}$ In the past couple of years, increasing research in the topic of diversity in graduate medical education has shed light on this important topic raising significant awareness. As a result, new initiatives have been built around the topic and are widely available for Hispanic women training in the U.S. ${ }^{(18)}$

Urologists for Equity, a group centered leadership was developed in order to create a community to propel meaningful changes in diversity, equity and inclusion in our field. ${ }^{(18)}$ Society of Women in Urology, which started in 1980 by five female urologists, is currently a large and key group for women at all levels of training in urology. It comprises the largest and strongest mentorship group of female urologists. An active society that offers an annual meeting with multiple opportunities for women and URM to network and share research ideas. But most importantly has opened a formal space for mentorship, grant funding and advocacy. ${ }^{(1,18)}$ The Society of Academic Urologists created a task force in 2018 called "Recruitment and Retention of Women and Underrepresented Minorities in Urology LatinX in Urology, ${ }^{(18)}$ created by two Latina medical students in 2020 who seized the opportunity offered by social media to connect LatinX urologists in the United States in order to create mentorship, celebrate LatinX urologists and in that way motivate other medical students of URM to pursue a career in urology. ${ }^{(18)}$

The R. Frank Jones Urology Interest Group ran by Urology Unbound are increasing national awareness and provide mentorship to women and URMs. ${ }^{(18)}$ The Under Represented Trainees Entering Residency (UReTER) program is a formal mentorship program developed in 2020 at the University of California, San Francisco (UCSF) as a resident led mentorship program 
that matched URM residents and fellows with URM medical students interested in urology during the residency application journey. ${ }^{(10)}$

Ongoing efforts of building a clinical and academic environment that welcomes a diverse group of trainees and urologists will increase the representation of URM women in urology and will attract and recruit more women to this field. ${ }^{(1)}$ Mathis et al highlight that there needs to be deliberate and active recruitment of diverse applicants and established effort to limit and prevent implicit bias when reviewing women and URMs residency applications and during the interview process. ${ }^{(3)}$ The authors in this study call for program directors and faculty to actively diversify their programs and also suggest training on implicit bias during resident application review and also provide a safe environment for female and URM students, residents, fellows and staff to provide networking, mentorship and collaboration. ${ }^{(3)}$ The value of increasing the Latina population in urology serves to achieve congruence between physicians and patients to provide better care, recruit diverse populations into clinical trials, and to continue innovation in urology.

Academic training institutions need to be more than "mindful" of diversity, equity and inclusion (DEI) which has been a recent tagline. Recruitment and advancement should be an active process. URM faculty need support to have time and resources to serve as mentors to medical students and trainees. Hospitals and clinics serving URM communities should seek healthcare providers who are congruent with the populations that they serve; this creates a demand that will encourage training of women and URM. In the last decades, there has been and increasing number Latina women in urolo- gy that have earned leadership positions in the U.S, opening a new door for younger generations as exemplary role models.

Awareness of international training standards and institutions should help program directors evaluate more fairly IMGs for consideration into urological training. Structural barriers like United States Medical Licensing Examination (USMLE) STEP scores becoming "pass fail" should favor consideration of other important factors like academic productiveness in research, community outreach and advocacy. There is no logical or scientific reason why the urology workforce should not mirror the population of the U.S.

\section{Funding}

No sponsorship was received to write this article.

\section{Conflict of interest:}

The authors declare no conflicts of interest.

\section{References}

1. Dai JC, Agochukwu-Mmonu N, Hittelman AB. Strategies for Attracting Women and Underrepresented Minorities in Urology. Curr Urol Rep. 2019;20(10):61. doi: 10.1007/s11934019-0921-5

2. Oberlin DT, Vo AX, Bachrach L, Flury SC. The Gender Divide: The Impact of Surgeon Gender on Surgical Practice Patterns in Urology. J Urol. 2016;196(5):1522-6. doi: 10.1016/j. juro.2016.05.030 
3. Marthi S, Enemchukwu E, Thavaseelan S. Defining theVariance:TheCurrentStateofFemale and URM Concordance of Urology Resident Workforce to the General U.S. Population. Urology. 2021;S0090-4295(21)00672-5. doi: 10.1016/j.urology.2021.06.039

4. Vespa J, Armstrong DM, Medina L, U.S. Census Bureau. Demographic turning points for the United States: population projections for 2020 to 2060. Washington, D.C: Current population reports; 2018.

5. Halpern JA, Lee UJ, Wolff EM, Mittal S, Shoag JE, Lightner DJ, et al. Women in Urology Residency, 1978-2013: A Critical Look at Gender Representation in Our Specialty. Urology. 2016;92:20-5. doi: 10.1016/j. urology.2015.12.092

6. American Urological Association. The State of the Urology Workforce and Practice in the United States. American Urological Association.; 2020.

7. Simons ECG, Thavaseelan S, Saigal C, Downs T. Diversifying Graduate Medical Education \& the Urology Workforce: Re-imagining our Structures, Policies, Practices, Norms, \& Values. Urology. 2021;S0090-4295(21)00554-9. doi: 10.1016/j.urology.2021.06.011

8. Shantharam G, Tran TY, McGee H, Thavaseelan S. Examining Trends in Underrepresented Minorities in Urology Residency. Urology. 2019;127:36-41. doi: 10.1016/j.urology.2018.10.061

9. Deville C, Hwang W-T, Burgos R, Chapman CH, Both S, Thomas CR. Diversity in Graduate Medical Education in the United States by Race, Ethnicity, and Sex, 2012. JAMA Intern Med. 2015;175(10):1706-8. doi: 10.1001/ jamainternmed.2015.4324
10. Zheng MY, Overland M, Escobar D, Fakunle M, Li Y, Chu C, et al. Formal Mentorship as an Opportunity to Expand the Urology Pipeline: Under Represented Trainees Entering Residency (UReTER) Program Evaluation 20202021. Urology. 2021;S0090-4295(21)00832-3. doi: 10.1016/j.urology.2021.06.052

11. Washington SL, Baradaran N, Gaither TW, Awad MA, Murphy GP, Downs TM, et al. Racial distribution of urology workforce in United States in comparison to general population. Transl Androl Urol. 2018;7(4):526-34. doi: $10.21037 /$ tau.2018.05.16

12. Wong D, Kuprasertkul A, Khouri RK, Ganesan V, Kenigsberg AP, Lemack GE. Assessing the Female and Underrepresented Minority Medical Student Experience in the Urology Match: Where Do We Fall Short? Urology. 2021;147:5763. doi: 10.1016/j.urology.2020.08.076

13. Halpern JA, Al Hussein Al Awamlh B, Mittal S, Shoag JE, Hu JC, Lee RK. International Medical Graduate Training in Urology: Are We Missing an Opportunity? Urology. 2016;95:39-46. doi: 10.1016/j.urology.2016.03.063

14. Weissbart SJ, Stock JA, Wein AJ. Program directors' criteria for selection into urology residency. Urology. 2015;85(4):731-6. doi: 10.1016/j.urology.2014.12.041

15. Nikonow TN, Lyon TD, Jackman SV, Averch TD. Survey of Applicant Experience and Cost in the Urology Match: Opportunities for Reform. J Urol. 2015;194(4):1063-7. doi: 10.1016/j. juro.2015.04.074

16. Chen PG-C, Curry LA, Bernheim SM, Berg D, Gozu A, Nunez-Smith M. Professional challenges of non-U.S.-born international medical graduates and recommendations for support during residency training. Acad Med. 2011;86(11):1383-8. doi: 10.1097/ ACM.0b013e31823035e1 
17. Kutikov A, Bonslaver J, Casey JT, Degrado J, Dusseault BN, Fox JA, et al. The Gatekeeper Disparity: Why Do Some Medical Schools Send More Medical Students into Urology? J Urol. 2011;185(2):647-52. doi: 10.1016/j. juro.2010.09.113
18. Cannon S, Seideman CA, Thavaseelan S, Wilson S, Zaila KE, Delgado J, et al. Urologists for Equity: A Collective Approach Toward Diversity, Equity, and Inclusion in Urology. Urology. 2021;S0090-4295(21)00706-8. doi: 10.1016/j.urology.2021.07.017 